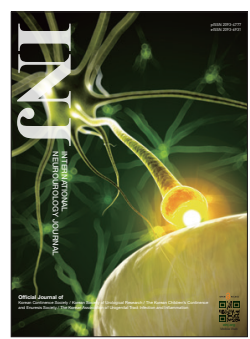

\title{
Postnatal Treadmill Exercise Alleviates Prenatal Stress-Induced Anxiety in Offspring Rats by Enhancing Cell Proliferation Through 5-Hydroxytryptamine 1A Receptor Activation
}

\author{
Sam Jun Lee ${ }^{1}$, Tae Woon Kim², Hun Kyung Park ${ }^{3}$, Sangyun Yoon ${ }^{3}$, Ann Hee You ${ }^{3}$ Eun Jin Moon ${ }^{3}$, Dong Hoon Shin ${ }^{4}$, Hanjin Cho ${ }^{5}$ \\ ${ }^{1}$ Department of Physical Education, College of Health, Welfare, and Education, Tong Myong University, Busan, Korea \\ ${ }^{2}$ Department of Physiology, College of Medicine, Kyung Hee University, Seoul, Korea \\ ${ }^{3}$ Department of Medicine, Graduate School, Kyung Hee University, Seoul, Korea \\ ${ }^{4}$ Department of Food and Biotechnology, Graduate School of Life Sciences and Biotechnology, Korea University, Seoul, Korea \\ ${ }^{5}$ Department of Emergency Medicine, Korea University Ansan Hospital, Korea University College of Medicine, Ansan, Korea
}

Purpose: Stress during pregnancy is a risk factor for the development of anxiety-related disorders in offspring later in life. The effects of treadmill exercise on anxiety-like behaviors and hippocampal cell proliferation were investigated using rats exposed to prenatal stress.

Methods: Exposure of pregnant rats to a hunting dog in an enclosed room was used to induce stress. Anxiety-like behaviors of offspring were evaluated using the elevated plus maze test. Immunohistochemistry for the detection of 5-bromo-2'deoxyuridine and doublecortin (DCX) in the hippocampal dentate gyrus and 5-hydroxytryptamine $1 \mathrm{~A}$ receptors $\left(5-\mathrm{HT}_{1 \mathrm{~A}}\right)$ in the dorsal raphe was conducted. Brain-derived neurotrophic factor (BDNF) and tyrosine kinase B (TrkB) levels in the hippocampus were evaluated by western blot analysis.

Results: Offspring of maternal rats exposed to stress during pregnancy showed anxiety-like behaviors. Offspring also showed reduced expression of BDNF, TrkB, and DCX in the dentate gyrus, decreased cell proliferation in the hippocampus, and reduced 5- $\mathrm{HT}_{1 \mathrm{~A}}$ expression in the dorsal raphe. Postnatal treadmill exercise by offspring, but not maternal exercise during pregnancy, enhanced cell proliferation and expression of these proteins.

Conclusions: Postnatal treadmill exercise ameliorated anxiety-like behaviors in offspring of stressed pregnant rats, and the alleviating effect of exercise on these behaviors is hypothesized to result from enhancement of cell proliferation through $5-\mathrm{HT}_{1 \mathrm{~A}}$ activation in offspring rats.

Keywords: Prenatal Exposure Delayed Effects; Exercise Test; Anxiety; Cell Proliferation; Serotonin

- Grant Support: This work was supported by a Korea University Grant (K1512651).

- Conflict of Interest: No potential conflict of interest relevant to this article was reported.

\section{INTRODUCTION}

Stress during pregnancy as well as stress exposure in early postnatal life induces physiological and behavioral changes in off- spring [1]. These changes may include the development of anxiety in offspring. Anxiety is accompanied by a constellation of behavioral and physiological defensive responses, including avoidance, vigilance, and arousal [2].
Corresponding author: Hanjin Cho (iD http://orcid.org/0000-0003-1303-304X Department of Emergency Medicine, Korea University Ansan Hospital, Korea University College of Medicine, 123 Jeokgeum-ro, Danwon-gu, Ansan 15355, Korea

E-mail: chohj327@korea.ac.kr / Tel: +82-31-412-5380 / Fax: +82-31-412-5315 Submitted: May 1, 2016 / Accepted after revision: May 12, 2016 
Alterations in markers of neuronal plasticity, such as brainderived neurotrophic factor (BDNF), and compromised serotonergic function through alterations in the levels of serotonin (5-hydroxytryptamine, 5-HT) and 5-hydroxytryptamine 1A receptors $\left(5-\mathrm{HT}_{1 \mathrm{~A}}\right)$ are implicated in anxiety disorders $[3,4]$. BDNF is a member of the neurotrophin family, and tyrosine kinase $\mathrm{B}(\mathrm{TrkB})$ is its receptor. $\mathrm{BDNF}$ and $\operatorname{TrkB}$ control neuronal plasticity, and they are associated with many psychological disorders [4-6]. 5-HT is a neurotransmitter involved in the pathogenesis of depression [7]. The 5- $\mathrm{HT}_{1 \mathrm{~A}}$ receptor is one of the 5-HT receptor subtypes and is abundantly expressed in the hippocampus. In a study of patients with depression, very low expression of 5- $\mathrm{HT}_{1 \mathrm{~A}}$ mRNA was observed [8]. In BDNF-deficient mice, mild stress-induced reduction in hippocampal 5- $\mathrm{HT}_{1 \mathrm{~A}}$ receptor expression is prevented by the selective serotonin reuptake inhibitor, fluoxetine, through activation of TrkB [9]. These results suggest that BDNF expression is closely linked to stressassociated mental disorders [9].

Hippocampal neurogenesis occurs throughout life, including adulthood, and is affected by many environmental factors [1012]. Adult hippocampal neurogenesis affects learning ability and memory processes, and diverse neuronal markers are expressed during the process of neurogenesis [13]. Among them is doublecortin (DCX), a brain-specific microtubule-associated protein [13]. The hippocampus is involved in cognitive processes and is important in the processing of emotion and modulation of anxiety states [14]. The level of 5-HT synthesis in the dorsal and median raphe plays a key role in mood disorders [15].

Exercise is known to exert beneficial effects on brain function and has been recommended as a useful strategy to manage anxiety and depression [16-18]. In the present study, the effects of treadmill exercise on anxiety-like behaviors and on cell proliferation were investigated using rats exposed to prenatal stress.

\section{MATERIALS AND METHODS}

\section{Animals and Treatments}

The experimental process was conducted in accordance with the animal care guidelines of the Korean Academy of Medical Sciences and the National Institutes of Health. Pregnant rats were assigned to 3 groups ( $n=5$ in each group): control group, stress-induced group, and stress-induced and exercise group. The offspring were assigned to 4 groups after delivery $(n=7$ in each group): Offspring in the maternal control group, offspring in the maternal stress group, offspring in the maternal stress with exercise group, and offspring with exercise in the maternal stress group. All offspring received $50 \mathrm{mg} / \mathrm{kg}$ of 5-bromo-2'deoxyuridine (BrdU) intraperitoneally once a day for 2 weeks, 30 minutes before the start of treadmill exercise.

\section{Stress Exposure of Pregnant Rats}

Exposure of maternal rats to a hunting dog in an enclosed room was used to induce stress in the pregnant rats, as described previously $[17,18]$. The exposure time was 10 minutes, and this process was repeated 3 times per day with a 1-hour interval between exposures. This regimen was initiated 7 days after the start of pregnancy and continued until delivery.

\section{Exercise Protocol}

Pregnant rats in the stress-induced and exercise group were forced to run on a treadmill for 30 minutes once a day, beginning 7 days after the onset of pregnancy and continuing until delivery. Rats in the offspring with exercise in the maternal stress group were forced to run on a treadmill for 30 minutes once a day, starting 4 weeks after birth and continuing for 4 weeks. Maternal rats and offspring ran at a speed of $2 \mathrm{~m} / \mathrm{min}$ for the first 5 minutes, $5 \mathrm{~m} / \mathrm{min}$ for the next 5 minutes, and 8 $\mathrm{m} / \mathrm{min}$ for the last 20 minutes, at $0^{\circ}$ inclination.

\section{Elevated Plus Maze Test}

Anxiety-related behaviors were evaluated using the elevated plus maze test as previously described [18]. The elevated plus maze apparatus consisted of two opposing open arms (45 $\mathrm{cm} \times 10 \mathrm{~cm})$ and two opposing closed arms $(45 \mathrm{~cm} \times 10 \mathrm{~cm} \times 50$ $\mathrm{cm})$, extending from a central platform $(10 \mathrm{~cm} \times 10 \mathrm{~cm})$ and elevated $65 \mathrm{~cm}$ above the floor. The rat was placed on the central platform facing a closed arm and then was allowed to freely explore the maze for 5 minutes. Time spent in the open and in the closed arms was determined.

\section{Tissue Preparation}

Offspring were sacrificed 80 weeks after birth, immediately after completing the elevated plus maze test. The rats were anesthetized with Zoletil 50 (10 mg/kg, intraperitoneally; Vibac Laboratories, Carros, France), and 50mM phosphate-buffered saline was perfused transcardially followed by a solution of $4 \%$ paraformaldehyde in 100mM phosphate buffer (PB, pH 7.4). Brain coronal sections of $40-\mu \mathrm{m}$ thickness were prepared using a freezing microtome (Leica, Nussloch, Germany). 


\section{Immunohistochemistry for BrdU}

BrdU-specific immunohistochemistry in the dentate gyrus was conducted as previously reported $[11,19]$. Tissue sections were incubated overnight at $4^{\circ} \mathrm{C}$ with $\mathrm{BrdU}$-specific mouse monoclonal antibody (1:600; Roche, Mannheim, Germany). The sections were then incubated with biotinylated mouse secondary antibody (1:200; Vector Laboratories, Burlingame, CA, USA) for 1 hour. For visualization, the sections were incubated in 50 $\mathrm{mM}$ Tris- $\mathrm{HCl}$ (pH 7.6) containing 0.02\% diaminobenzide, 40$\mathrm{mg} / \mathrm{mL}$ nickel chloride, and $0.03 \% \mathrm{H}_{2} \mathrm{O}_{2}$ for 5 minutes. After BrdU staining, the differentiation of BrdU-positive cells was evaluated on the same section using a mouse anti-NeuN antibody (1:1,000; Chemicon International, Temecula, CA, USA). Slides were then air-dried overnight at room temperature, and coverslips were mounted using Permount (Fisher Scientific, Fair Lawn, NJ, USA).

\section{Immunohistochemistry for $\mathrm{DCX}$ and $5 \mathrm{HT}_{1 \mathrm{~A}}$}

Immunohistochemistry for DCX in the dentate gyrus and for $5 \mathrm{HT}_{1 \mathrm{~A}}$ in the dorsal raphe was performed as in previous studies $[13,19]$. Sections were incubated overnight with rabbit antidoublecortin antibody $(1 \mu \mathrm{g} / \mathrm{mL}$; Santa Cruz Biotechnology, Santa Cruz, CA, USA) or rabbit anti-5-HT ${ }_{1 \mathrm{~A}}$ antibody (1:500; Abcam, Cambridge, UK). Slides were then incubated with biotinylated rabbit secondary antibody (1:200; Vector Laboratories) for one hour. The secondary antibody was amplified with the Vector Elite ABC kit (1:100; Vector Laboratories). Following amplification, slides were air-dried overnight at room temperature, and coverslips were mounted using Permount (Fisher Scientific).

\section{Western Blot for BDNF and TrkB}

Expression of BDNF and TrkB was determined by western blot analysis, as described previously [6,20]. Hippocampal tissues were homogenized in lysis buffer. Protein $(30 \mu \mathrm{g})$ was separated on sodium dodecyl sulfate-polyacrylamide gels, and then transferred onto a nitrocellulose membrane. Rabbit anti-BDNF (1:1,000; Santa Cruz Biotechnology), rabbit anti-TrkB (1:1,000; Santa Cruz Biotechnology), and mouse anti- $\beta$-actin $(1: 1,000$; Santa Cruz Biotechnology) antibodies were used as primary antibodies. Horseradish peroxidase-conjugated antimouse antibody for $\beta$-actin and antirabbit antibody for BDNF and TrkB were used as secondary antibodies.

\section{Data Analysis}

The numbers of BrdU-positive and DCX-positive cells in the dentate gyrus were expressed as number of cells per $\mathrm{mm}^{2}$ in the dentate gyrus. Number of $5-\mathrm{HT}_{1 \mathrm{~A}}$-positive cells in the dorsal raphe was expressed as the number of cells per section. Relative expressions of BDNF and TrkB were measured densitometrically using Molecular Analyst ver. 1.4.1 (Bio-Rad, Hercules, CA, USA). Data were analyzed using one-way analysis of variance and Duncan post hoc tests. Results are expressed as the mean \pm standard error of the mean and P-value $<0.05$ was considered significant.

\section{RESULTS}

\section{Effect of Treadmill Exercise on Anxiety-Like Behaviors}

Time spent in the open arms was shorter in offspring exposed to prenatal stress compared to offspring not exposed to prenatal stress. Offspring with exercise in the maternal stress group spent more time in the open arms than offspring in the maternal stress group. However, offspring in the maternal stress with exercise group did not spend more time in the open arms (Fig. 1).

\section{Effect of Treadmill Exercise on BDNF and TrkB Expression in Hippocampus}

BDNF and TrkB levels were suppressed in offspring exposed to prenatal stress compared to offspring not exposed to prenatal stress (Fig. 2). Offspring with exercise in the maternal stress group showed increased BDNF and TrkB expression than offspring in the maternal stress group. Offspring of the maternal stress with exercise group did not show increased BDNF and TrkB expression.

\section{Effect of Treadmill Exercise on Cell Proliferation in Hippocampal Dentate Gyrus}

Cell proliferation was suppressed in offspring exposed to prenatal stress compared to offspring not exposed to prenatal stress. Offspring with exercise in the maternal stress group showed increases in cell proliferation than offspring in the maternal stress group. Offspring in the maternal stress with exercise group did not show increases in cell proliferation (Fig. 3).

\section{Effect of Treadmill Exercise on DCX Expression in Hippocampal Dentate Gyrus}

DCX expression was suppressed in offspring exposed to prenatal stress compared to offspring not exposed to prenatal stress. Offspring with exercise in the maternal stress group showed increases in DCX expression than offspring in the maternal stress 

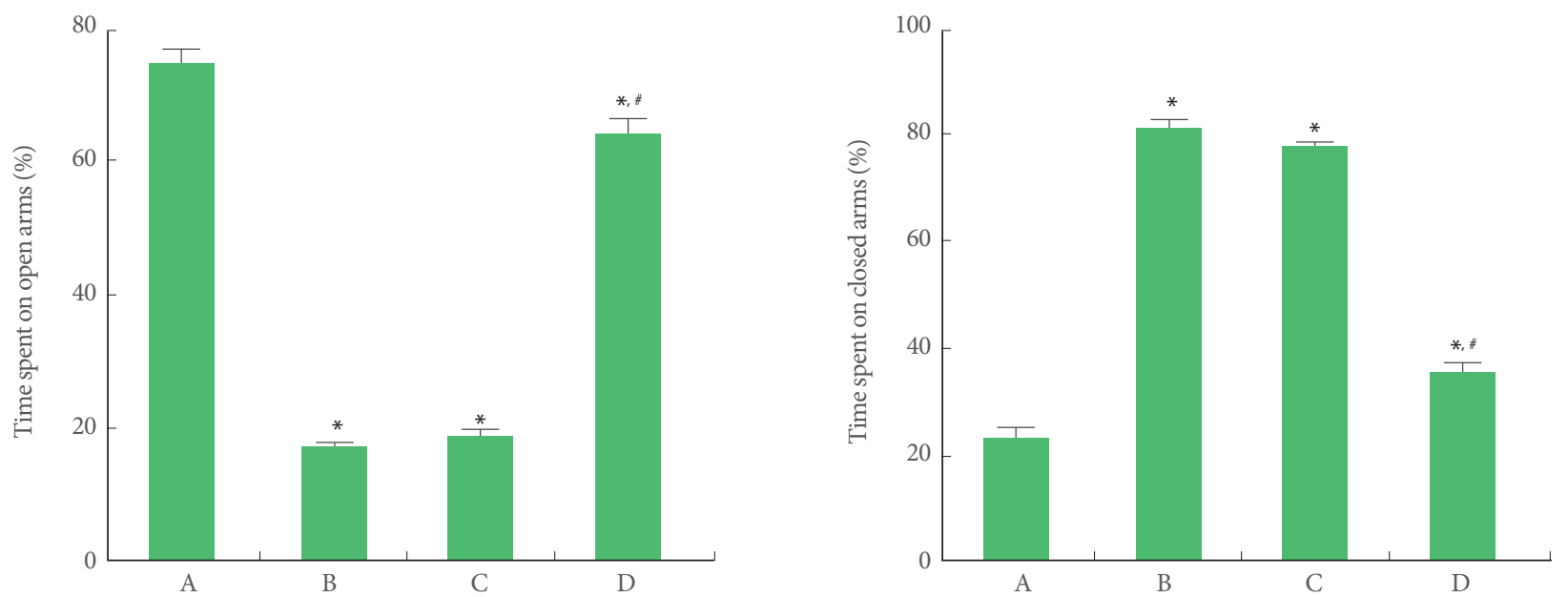

Fig. 1. Effect of treadmill exercise on anxiety-like behaviors in the elevated plus maze test. A, Offspring in the maternal control group; $\mathrm{B}$, offspring in the maternal stress group; $\mathrm{C}$, offspring in the maternal stress with exercise group; $\mathrm{D}$, offspring with exercise in the maternal stress group. ${ }^{*} \mathrm{P}<0.05$ compared to the offspring in the maternal control group. ${ }^{*} \mathrm{P}<0.05$ compared to the offspring in the maternal stress group.

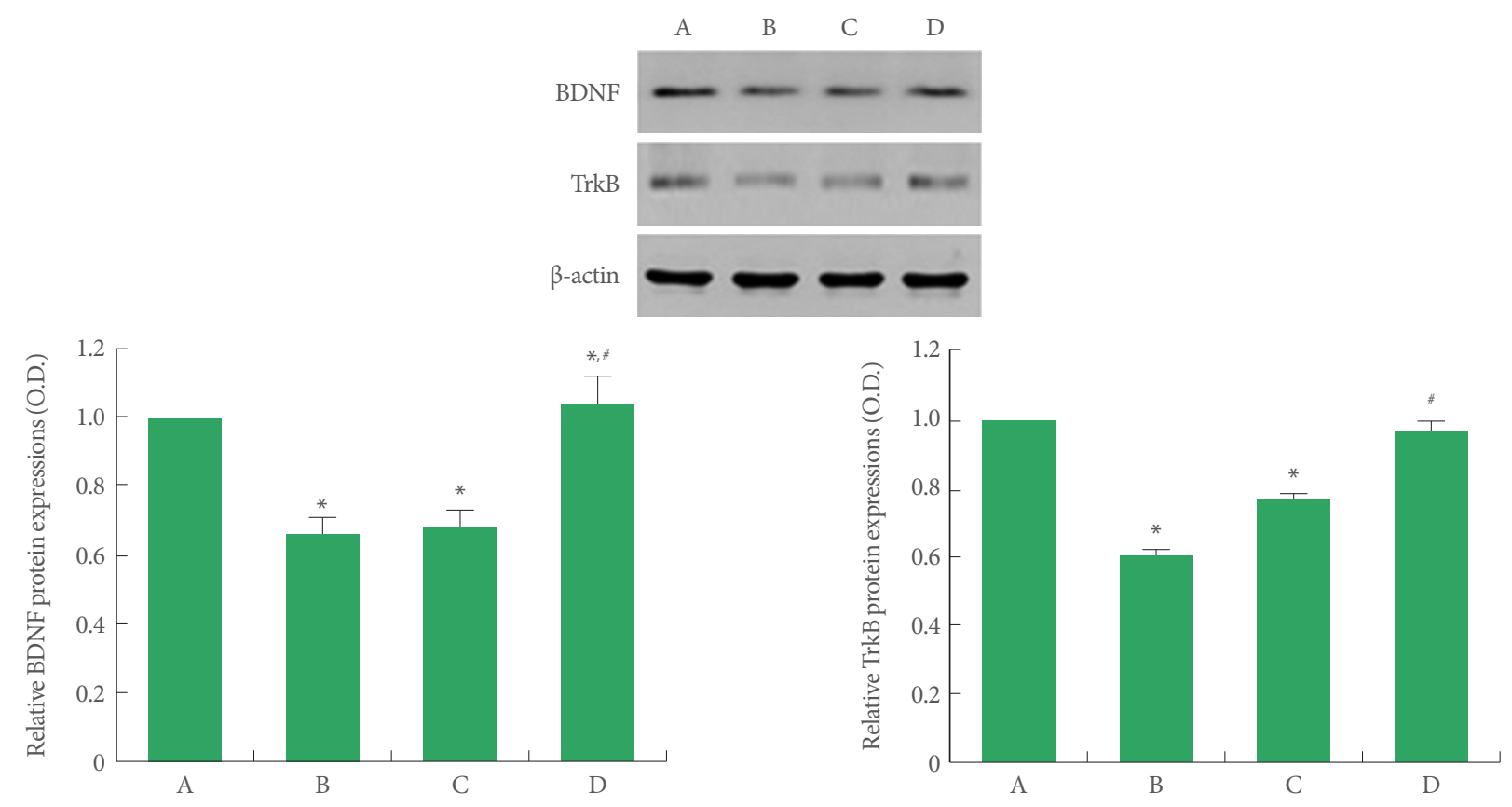

Fig. 2. Effect of treadmill exercise on brain-derived neurotrophic factor and tyrosine kinase B expression in the hippocampus. A, Offspring in the maternal control group; B, offspring in the maternal stress group; $\mathrm{C}$, offspring in the maternal stress with exercise group; $\mathrm{D}$, offspring with exercise in the maternal stress group. BDNF, brain-derived neurotrophic factor; TrkB, tyrosine kinase $\mathrm{B}$. ${ }^{*} \mathrm{P}<0.05$ compared to the offspring in the maternal control group. ${ }^{\#} \mathrm{P}<0.05$ compared to the offspring in the maternal stress group.

group. Offspring in the maternal stress with exercise group did not show increases in DCX expression (Fig. 4).
Effect of Treadmill Exercise on 5-HT ${ }_{1 \mathrm{~A}}$ Expression in Dorsal Raphe

5- $\mathrm{HT}_{1 \mathrm{~A}}$ expression was decreased in offspring exposed to prenatal stress compared to offspring not exposed to prenatal 

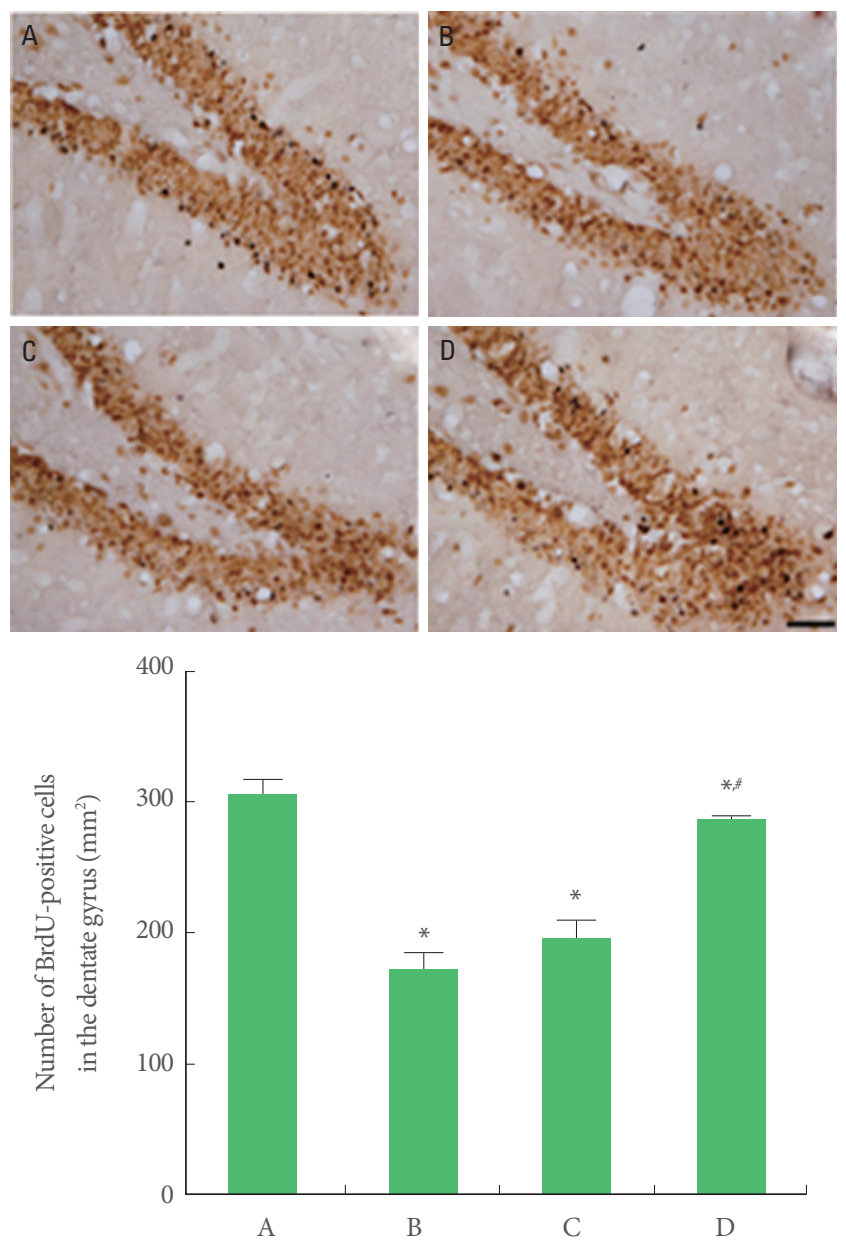

Fig. 3. Effect of treadmill exercise on cell proliferation in the hippocampal dentate gyrus. Upper: Photomicrographs of 5-bromo-2'-deoxyuridine (BrdU)-positive cells. The scale bar represents $50 \mu \mathrm{m}$. Lower: Number of BrdU-positive cells in each group. A, Offspring in the maternal control group; B, offspring in the maternal stress group; $\mathrm{C}$, offspring in the maternal stress with exercise group; $\mathrm{D}$, offspring with exercise in the maternal stress group. ${ }^{*} \mathrm{P}<0.05$ compared to the offspring in the maternal control group. ${ }^{*} \mathrm{P}<0.05$ compared to the offspring in the maternal stress group.

stress. Offspring with exercise in the maternal stress group showed increases in 5- $\mathrm{HT}_{1 \mathrm{~A}}$ expression than offspring in the maternal stress group. Offspring in the maternal stress with exercise group did not show increases in 5- $\mathrm{HT}_{1 \mathrm{~A}}$ expression (Fig. 5).

\section{DISCUSSION}

Prenatal stress is associated with a higher susceptibility to mental illnesses, such as anxiety, which persist throughout postnatal
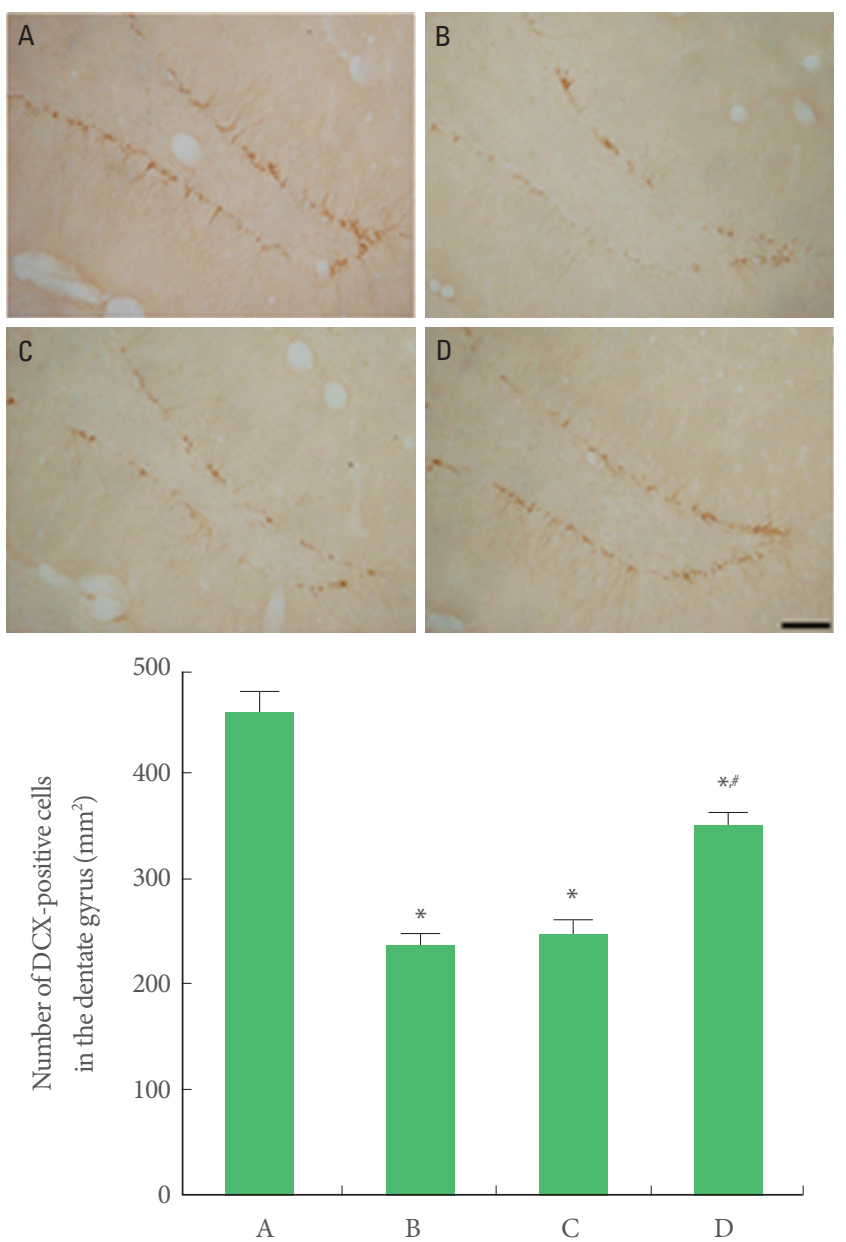

Fig. 4. Effect of treadmill exercise on doublecortin (DCX) expression in the hippocampal dentate gyrus. Upper: Photomicrographs of DCX-positive cells. The scale bar represents 100 $\mu \mathrm{m}$. Lower: Number of DCX-positive cells in each group. A, Offspring in the maternal control group; $\mathrm{B}$, offspring in the maternal stress group; $\mathrm{C}$, offspring in the maternal stress with exercise group; $\mathrm{D}$, offspring with exercise in the maternal stress group. ${ }^{*} \mathrm{P}<0.05$ compared to the offspring in the maternal control group. ${ }^{\#} \mathrm{P}<0.05$ compared to the offspring in the maternal stress group.

life [21]. The elevated plus maze test is designed to determine the severity of anxiety in rodents, and animals exposed to stress show a reduced duration in the open arms and an increased duration in the closed arms [18]. In this study, rats exposed to prenatal stress spent less time in the open arms and more time in the closed arms, suggesting elevated anxiety-like behavior. Postnatal treadmill exercise by offspring inhibited anxiety-like behaviors as demonstrated in the results from the elevated plus maze. In contrast, maternal treadmill exercise during pregnan- 

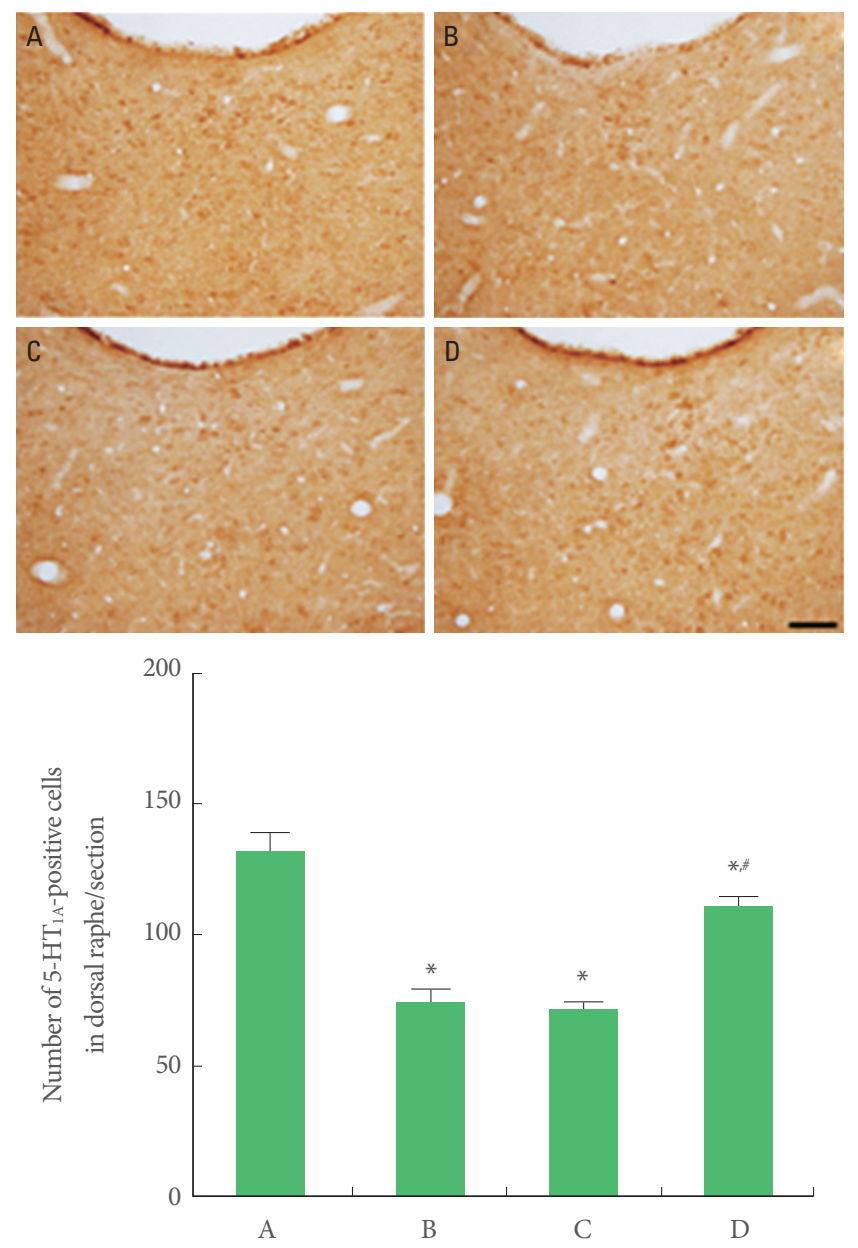

Fig. 5. Effect of treadmill exercise on 5-hydroxytryptamine 1A receptor $\left(5-\mathrm{HT}_{1 \mathrm{~A}}\right)$ expression in the dorsal raphe. Upper: Photomicrographs of 5- $\mathrm{HT}_{1 \mathrm{~A}}$-positive cells. The scale bar represents $100 \mu \mathrm{m}$. Lower: The number of 5- $\mathrm{HT}_{1 \mathrm{~A}}$-positive cells in each group. A, Offspring in the maternal control group; B, offspring in the maternal stress group; $\mathrm{C}$, offspring in the maternal stress with exercise group; $\mathrm{D}$, offspring with exercise in the maternal stress group. ${ }^{*} \mathrm{P}<0.05$ compared to the offspring in the maternal control group. ${ }^{*} \mathrm{P}<0.05$ compared to the offspring in the maternal stress group.

cy did not inhibit anxiety-like behaviors in offspring.

Prenatal stress is also known to induce alterations in hippocampal synaptic plasticity, demonstrated by suppression of BDNF expression [22] and inhibition of neurogenesis [23]. BDNF-heterozygous mice and mice with impaired hippocampal neurogenesis exhibit anxiety-like behaviors [14,24]. Treadmill exercise reduces anxiety-like behavior and enhances neurogenesis in the hippocampus [25]. Treadmill exercise also increases expression of BDNF in rats with stress-induced depres- sion [26]. In this study, the offspring of rats exposed to stress during pregnancy showed low hippocampal expression of BDNF and TrkB. However, postnatal treadmill exercise increased expressions of BDNF and TrkB in offspring. Similar to behavioral results, maternal treadmill exercise during pregnancy did not affect BDNF and TrkB expression in offspring.

Decreased cell proliferation and suppressed DCX expression in the hippocampus are closely related with many neuropsychological disorders, and treadmill exercise increases cell proliferation and DCX expression, thereby alleviating neuropsychological symptoms $[13,18,19,27]$. In the present study, the offspring of rats exposed to stress during pregnancy exhibited reduction in cell proliferation and suppression of DCX expression in the hippocampus. Cell proliferation and DCX expression were enhanced when offspring completed the postnatal exercise regimen but were not affected by maternal exercise during pregnancy.

Mood disorders, such as anxiety and depression, are associated with serotonergic dysfunction [28]. 5- $\mathrm{HT}_{1 \mathrm{~A}}$ receptor knockout mice display increased anxiety-like behaviors [3]. Treadmill exercise alleviates stress-evoked impairment of social interaction by enhancing BDNF expression in the hippocampus via activation of 5- $\mathrm{HT}_{1 \mathrm{~A}}$ receptors [6]. In this study, offspring of rats exposed to stress during pregnancy showed reduced $5-\mathrm{HT}_{1 \mathrm{~A}}$ expression in the dorsal raphe, but postnatal treadmill exercise enhanced $5-\mathrm{HT}_{1 \mathrm{~A}}$ expression. In contrast, maternal treadmill exercise during pregnancy did not increase $5-\mathrm{HT}_{1 \mathrm{~A}}$ expression in offspring.

The anxiolytic action of treadmill exercise might be related to its effects on serotonergic function [10,29]. Treadmill exercise increases 5 -HT synthesis by up-regulation of $5-\mathrm{HT}_{1 \mathrm{~A}}$ receptors, alleviating depressive symptoms caused by stress [29]. Our study shows that offspring born to maternal rats exposed to stress during pregnancy exhibit anxiety-like behaviors, and though maternal treadmill exercise during pregnancy fails to reduce anxiety-like behaviors in offspring, postnatal treadmill exercise ameliorates these behaviors. These results align with hypotheses that treadmill exercise enhances cell proliferation via $5-\mathrm{HT}_{1 \mathrm{~A}}$ activation, thereby alleviating anxiety-like behaviors in rats.

\section{REFERENCES}

1. Götz AA, Stefanski V. Psychosocial maternal stress during pregnancy affects serum corticosterone, blood immune parameters and 
anxiety behaviour in adult male rat offspring. Physiol Behav 2007; 90:108-15.

2. Gross C, Hen R. The developmental origins of anxiety. Nat Rev Neurosci 2004;5:545-52.

3. Gross C, Zhuang X, Stark K, Ramboz S, Oosting R, Kirby L, et al. Serotonin1A receptor acts during development to establish normal anxiety-like behaviour in the adult. Nature 2002;416:396-400.

4. Mattson MP, Maudsley S, Martin B. BDNF and 5-HT: a dynamic duo in age-related neuronal plasticity and neurodegenerative disorders. Trends Neurosci 2004;27:589-94.

5. Castrén E, Rantamäki T. The role of BDNF and its receptors in depression and antidepressant drug action: reactivation of developmental plasticity. Dev Neurobiol 2010;70:289-97.

6. Kim TW, Lim BV, Kim K, Seo JH, Kim CJ. Treadmill exercise alleviates stress-induced impairment of social interaction through 5-hydroxytryptamine 1A receptor activation in rats. J Exerc Rehabil 2015;11:192-7.

7. Cowen PJ. Serotonin and depression: pathophysiological mechanism or marketing myth? Trends Pharmacol Sci 2008;29:433-6.

8. Meltzer CC, Price JC, Mathis CA, Butters MA, Ziolko SK, MosesKolko E, et al. Serotonin $1 \mathrm{~A}$ receptor binding and treatment response in late-life depression. Neuropsychopharmacology 2004; 29:2258-65.

9. Burke TF, Advani T, Adachi M, Monteggia LM, Hensler JG. Sensitivity of hippocampal 5- $\mathrm{HT}_{1 \mathrm{~A}}$ receptors to mild stress in BDNFdeficient mice. Int J Neuropsychopharmacol 2013;16:631-45.

10. Baek SS, Jun TW, Kim KJ, Shin MS, Kang SY, Kim CJ. Effects of postnatal treadmill exercise on apoptotic neuronal cell death and cell proliferation of maternal-separated rat pups. Brain Dev 2012;34:45-56.

11. Kim SE, Ko IG, Kim BK, Shin MS, Cho S, Kim CJ, et al. Treadmill exercise prevents aging-induced failure of memory through an increase in neurogenesis and suppression of apoptosis in rat hippocampus. Exp Gerontol 2010;45:357-65.

12. Sung YH, Shin MS, Cho S, Baik HH, Jin BK, Chang HK, et al. Depression-like state in maternal rats induced by repeated separation of pups is accompanied by a decrease of cell proliferation and an increase of apoptosis in the hippocampus. Neurosci Lett 2010;470: 86-90.

13. Kim SE, Ko IG, Park CY, Shin MS, Kim CJ, Jee YS. Treadmill and wheel exercise alleviate lipopolysaccharide-induced short-term memory impairment by enhancing neuronal maturation in rats. Mol Med Rep 2013;7:31-6.

14. Revest JM, Dupret D, Koehl M, Funk-Reiter C, Grosjean N, Piazza $\mathrm{PV}$, et al. Adult hippocampal neurogenesis is involved in anxiety- related behaviors. Mol Psychiatry 2009;14:959-67.

15. Lopez-Figueroa AL, Norton CS, Lopez-Figueroa MO, ArmelliniDodel D, Burke S, Akil H, et al. Serotonin 5- $\mathrm{HT}_{1 \mathrm{~A}}, 5-\mathrm{HT}_{1 \mathrm{~B}}$, and $5-\mathrm{HT}_{2 \mathrm{~A}}$ receptor mRNA expression in subjects with major depression, bipolar disorder, and schizophrenia. Biol Psychiatry 2004;55: 225-33.

16. De Moor MH, Beem AL, Stubbe JH, Boomsma DI, De Geus EJ. Regular exercise, anxiety, depression and personality: a populationbased study. Prev Med 2006;42:273-9.

17. Kim TW, Ji ES, Kim TW, Lee SW, Lee CY, Lee SJ. Postnatal treadmill exercise attenuates prenatal stress-induced apoptosis through enhancing serotonin expression in aged-offspring rats. J Exerc Rehabil 2015;11:12-9.

18. Seo JH, Kim TW, Kim CJ, Sung YH, Lee SJ. Treadmill exercise during pregnancy ameliorates post-traumatic stress disorder-induced anxiety-like responses in maternal rats. Mol Med Rep 2013;7:38995.

19. Kim YM, Ji ES, Kim SH, Kim TW, Ko IG, Jin JJ, et al. Treadmill exercise improves short-term memory by enhancing hippocampal cell proliferation in quinolinic acid-induced Huntington's disease rats. J Exerc Rehabil 2015;11:5-11.

20. Kim DH, Ko IG, Kim BK, Kim TW, Kim SE, Shin MS, et al. Treadmill exercise inhibits traumatic brain injury-induced hippocampal apoptosis. Physiol Behav 2010;101:660-5.

21. Huizink AC, Mulder EJ, Buitelaar JK. Prenatal stress and risk for psychopathology: specific effects or induction of general susceptibility? Psychol Bull 2004;130:115-42.

22. Yeh CM, Huang CC, Hsu KS. Prenatal stress alters hippocampal synaptic plasticity in young rat offspring through preventing the proteolytic conversion of pro-brain-derived neurotrophic factor (BDNF) to mature BDNF. J Physiol 2012;590:991-1010.

23. Lucassen PJ, Bosch OJ, Jousma E, Kromer SA, Andrew R, Seckl JR, et al. Prenatal stress reduces postnatal neurogenesis in rats selectively bred for high, but not low, anxiety: possible key role of placental 11beta-hydroxysteroid dehydrogenase type 2. Eur J Neurosci 2009;29:97-103.

24. Chen ZY, Jing D, Bath KG, Ieraci A, Khan T, Siao CJ, et al. Genetic variant BDNF (Val66Met) polymorphism alters anxiety-related behavior. Science 2006;314:140-3.

25. Trejo JL, Llorens-Martín MV, Torres-Aleman I. The effects of exercise on spatial learning and anxiety-like behavior are mediated by an IGF-I-dependent mechanism related to hippocampal neurogenesis. Mol Cell Neurosci 2008;37:402-11.

26. Lee TH, Kim K, Shin MS, Kim CJ, Lim BV. Treadmill exercise alleviates chronic mild stress-induced depression in rats. J Exerc Reha- 
bil 2015;11:303-10.

27. Heo YM, Shin MS, Lee JM, Kim CJ, Baek SB, Kim KH, et al. Treadmill exercise ameliorates short-term memory disturbance in scopolamine-induced amnesia rats. Int Neurourol J 2014;18:16-22.

28. Stamford JA, Davidson C, McLaughlin DP, Hopwood SE. Control of dorsal raphé 5-HT function by multiple 5-HT1 autoreceptors: parallel purposes or pointless plurality? Trends Neurosci 2000;23: 459-65.

29. Kim TW, Lim BV, Baek D, Ryu DS, Seo JH. Stress-induced depression is alleviated by aerobic exercise through up-regulation of 5-hydroxytryptamine 1A receptors in rats. Int Neurourol J 2015;19:2733. 